\title{
Aldeia, Matemática e Escola Indígena: apropriação de práticas discursivas por estudantes Pataxó
}

\author{
Village, Mathematics and Indigenous School: appropriation of discursive practices by \\ Pataxó students
}

\author{
Ruana Priscila da Silva Brito ${ }^{1}$ \\ Maria da Conceição Ferreira Reis Fonseca ${ }^{2}$
}

\section{Resumo}

O estudo que aqui apresentamos analisa como apropriação de práticas discursivas de e sobre matemática os posicionamentos de licenciandos e de licenciandas da etnia Pataxó de um Curso de Formação Intercultural para Educadores Indígenas, configurados em jogos discursivos que contemplam relações entre matemática tradicional (das aldeias) e a matemática escolar, e entre a educação escolar e a educação escolar indígena. Esses posicionamentos são tomados como disposição metacognitiva de natureza não apenas semântica, mas pragmática. O material empírico deste estudo foi produzido no acompanhamento de uma turma de licenciatura em matemática de um Curso Intercultural, em que foram adotados procedimentos etnográficos. Na seleção e no tratamento desse material, recorremos a referências da análise dialógica do discurso. Os posicionamentos assumidos pelos(as) licenciandos(as) indígenas nos obrigam a refletir sobre as possibilidades de uma Educação Escolar Indígena na qual sejam contemplados, para além das habilidades matemáticas individuais, os diferentes modos culturais de significar e construir formas próprias de participar de práticas sociais que envolvem matemática.

Palavras-chave: Apropriação de práticas sociais; práticas discursivas da matemática escolar; matemática tradicional indígena; educação escolar indígena.

\begin{abstract}
This study analyzes positions of Pataxó students of a Intercultural Teaching Course for Indigenous Educators as appropriation of discursive practices of and on mathematics. Those positions are configured in discursive games that contemplate relations between traditional mathematics (of the villages) and school mathematics and between school education and indigenous school education. In this analysis, they are taken as a metacognitive disposition whose nature is not only semantic, but pragmatic. The empirical material of this study was produced in the accompaniment of a Intercultural Teaching Graduate Course in Mathematics. Ethnographic procedures were adopted. The selection and treatment of the empirical material used references of dialogic analysis of discourse. The positions taken by the indigenous licentiates oblige us to reflect on the possibilities of an Indigenous School Education in which, besides the individual mathematical skills, the different cultural ways of meaning and constructing own forms of participation in practices that involve mathematics are contemplated.
\end{abstract}

\footnotetext{
1 Mestre e Doutoranda em Educação pela Universidade Federal de Minas Gerais (UFMG). Professora do "Centro Pedagógico" - Escola de Educação Básica e Profissional da UFMG (CP/EBAP/UFMG), Belo Horizonte-MG, Brasil. Endereço para correspondência: Núcleo Básico - CP/EBAP/UFMG - Av. Antônio Carlos, 6627, Campus Pampulha, Belo Horizonte-MG. CEP: 31.270-901. E-mail: ruanabrito@gmail.com

2 Doutora em Educação pela Unicamp. Professora Titular da Faculdade de Educação (FaE) da Universidade Federal de Minas Gerais (UFMG). Belo Horizonte-MG, Brasil. Endereço para correspondência: DMTE/FaE/UFMG - Av. Antônio Carlos, 6627, Campus Pampulha, Belo Horizonte-MG. CEP: 31.270-901. Email: mcfrfon@gmail.com
} 
DOI: https://doi.org/ 10.20396/zet.v26i1.8650482

Keywords: Appropriation of social practices; discursive practices of school mathematics; traditional indigenous mathematics; indigenous school education.

\section{Proposição do problema e referências teórico-metodológicas}

A reflexão que aqui propomos originou-se numa investigação sobre diferentes modos de apropriação de práticas discursivas da matemática escolar em um Curso de Formação Intercultural para Educadores Indígenas para a docência de matemática ${ }^{3}$. Este artigo tematiza a apropriação de práticas discursivas da matemática por estudantes Pataxó desse curso, analisando as relações que estabelecem entre conhecimento matemático tradicional de aldeias indígenas e conhecimento matemático escolar, ambos tomados como práticas sociais. Ao focalizar as diferentes práticas matemáticas como práticas sociais, este texto insere-se nos "esforços na busca de identificar, compreender e fomentar modos culturais de matematicar em diversos campos da vida social (até mesmo na escola) e de considerá-los em suas intenções, condições e repercussões" (Fonseca, 2009, p.53).

É, pois, nesse esforço que procuramos compreender as narrativas de indígenas em formação docente sobre práticas matemáticas tradicionais, e suas considerações sobre as possibilidades e as interdições da inserção dessas práticas tradicionais nas práticas pedagógicas da escola. Nesse mesmo esforço, reconhecemos tais narrativas como processos de apropriação de práticas discursivas - da matemática escolar ${ }^{4}$, do movimento indígena, da educação escolar indígena - na medida em que apontam a disposição metacognitiva de educadores e educadoras indígenas em formação quando refletem sobre a "maneira contrastada como os grupos e os indivíduos fazem uso dos motivos ou das formas que compartilham com outros" (Chartier, 2003, p.13).

Entendemos que é procurando abordar a matemática como produção cultural que as ações de formação de cursos de licenciaturas interculturais têm contemplado as práticas matemáticas indígenas, entendendo-as numa perspectiva que se aproxima da que lhe confere Mariana Kawall Ferreira (2002), quando as toma como formas culturalmente distintas de "manejar quantidades, números, medidas, formas e relações geométricas nas atividades do cotidiano como a cestaria, a tecelagem, a pintura corporal e a compra e venda de produtos" (Ferreira, 2002 p.7).

A relevância da dimensão cultural nessa perspectiva nos obriga a refletir sobre como povos minoritários, nesse caso, os povos indígenas, confrontam atividades escolares (também reconhecidas como práticas culturais) com seus conhecimentos práticos e/ou tradicionais do

\footnotetext{
${ }^{3}$ Esse curso tem como objetivo formar e habilitar professores indígenas em Licenciatura Plena, com enfoque intercultural, para lecionar nos anos finais do Ensino Fundamental e no Ensino Médio, com áreas de concentração em Línguas, Artes e Literaturas; Matemática; Ciências da Natureza; Ciências Sociais e Humanidades. Ele se dirige à população indígena que ainda não teve a oportunidade de se qualificar para a profissão de educador em curso superior.
}

4 Ao utilizarmos a expressão "práticas matemáticas escolares" referimo-nos não exatamente às práticas que ocorrem na escola, mas àquelas legitimadas pela cultura escolar. 
dia a dia nas aldeias, tanto quando assumem posições como estudantes de um curso de formação superior quanto quando desenvolvem suas tarefas de professores/as nas escolas indígenas.

Assim, neste artigo, são analisados alguns eventos em que licenciandos e licenciandas desse Curso, homens e mulheres da etnia Pataxó da aldeia Barra Velha, localizada no sul da Bahia, elaboram relatos sobre práticas matemáticas que vivenciavam ou testemunhavam em suas aldeias. Se aqui trazemos extratos das transcrições de aulas de matemática nas quais esses licenciandos se dispõem a falar de situações em que identificam ideias matemáticas nas práticas tradicionais das aldeias, devemos, contudo, esclarecer que o contexto da investigação envolveu não apenas as aulas das disciplinas específicas para licenciandos em Matemática ou o conjunto de atividades de formação que lhes é proposto nos tempos em que permanecem na universidade ou mesmo nos intermódulos que acontecem nas aldeias, mas todo o jogo discursivo que envolve a proposição e o desenvolvimento desse curso de licenciatura que visa a Educação Escolar Indígena.

Acerca dos caminhos metodológicos do estudo, foi produzido um Diário de Narrativas, composto a partir dos apontamentos do Diário de Campo, que eram textualizados e acrescidos da transcrição de interações discursivas selecionadas da gravação em áudio e vídeo das atividades da turma que acompanhamos. As narrativas referiam-se, principalmente, às interações com e entre indígenas em formação docente daquele curso, nas quais identificamos instâncias de apropriação de diferentes práticas discursivas.

\section{Apropriação de práticas discursivas}

Para identificar e discutir posicionamentos assumidos por indígenas em formação docente configurados em jogos discursivos sobre escola, matemática e educação escolar indígena, buscamos empreender uma análise dialógica do discurso, referenciadas nos autores do círculo de Bakhtin, considerando a "indissolúvel relação existente entre língua e linguagem, histórias e sujeitos, e uma concepção de linguagem, de construção e produção de sentidos necessariamente apoiadas nas relações discursivas empreendidas por sujeitos historicamente situados" (Bakhtin apud Brait, 2006, p.10).

Nesse processo analítico, nós nos dedicamos à análise das interações discursivas em que os enunciados foram proferidos, sempre procurando analisar a situação discursiva, uma vez que

as relações dialógicas são absolutamente impossíveis sem relações lógicas e concretosemânticas, mas são irredutíveis a estas e têm especificidade própria. Para se tornarem dialógicas, as relações lógicas e concreto-semânticas devem, como já dissemos, materializar-se, ou seja, devem passar a outro campo de existência, devem tornar-se discurso, ou seja, enunciado e ganhar autor, criador de dado enunciado cuja posição expressa (Bakhtin apud Brait, 2006, p.13). 
Nesse sentido, nos reportamos ao modo como Bakhtin propõe a análise de discursos, buscando captar "particularidades discursivas que apontam para contextos mais amplos, para um extralinguístico aí incluído” (Bakhtin apud Brait, 2006, p.13).

É nesta perspectiva que empreendemos a análise desta investigação, ora tentando "esmiuçar campos semânticos, descrever e analisar micro e macroorganizações sintáticas", ora procurando "reconhecer, recuperar e interpretar marcas e articulações enunciativas que caracterizam o(s) discurso(s) e indicam sua heterogeneidade constitutiva, assim como as dos sujeitos aí instalados" (Bakhtin apud Brait, 2006, p.13).

O conceito de apropriação (de práticas) assumido nesta investigação, não é entendido como mera internalização ou adaptação, mas sua dimensão semântica é inserida num processo pragmático por meio do qual sujeitos sociais atribuem significados às práticas que protagonizam.

Acreditamos que esses processos de apropriação de práticas discursivas não podem ser caracterizados como mera assimilação de expressões linguísticas e conteúdos temáticos ou como adaptação a padrões e normas. As análises que tecemos a respeito desses processos reforçam a preocupação - também destacada nos estudos de Smolka (2000) - de relacionarmos os processos de apropriação ao problema da significação, conferindo-lhe uma dimensão pragmática (não se restringindo assim a uma significação semântica), uma vez que afetados, de diferentes modos, pelas muitas formas de produção nas quais eles participam, também de diferentes maneiras, os sujeitos apropriam-se de discursos e os mobilizam pragmaticamente, convertendo as palavras alheias em próprias, opondo à palavra do locutor uma contrapalavra (Bakhtin, 1997; 1997a). Ao apropriarem-se de práticas discursivas os sujeitos assumem posições nos jogos interlocutivos que, estabelecidos como relações sociais, são sempre jogos de poder (Brito e Fonseca, 2017).

\section{"Matemática no Calendário do Conhecimento Pataxó": o discurso sobre as práticas tradicionais e a apropriação de práticas escolares}

O evento, ocorrido no dia 15 de dezembro de 2011, durante a última etapa intermediária de que participamos, na Aldeia Indígena Pataxó - Barra Velha/BA, constitui-se das interações forjadas a partir da proposição de uma atividade que visava identificar certos conceitos matemáticos inseridos nas práticas matemáticas da aldeia, como estratégia para promover a aproximação daqueles alunos e daquelas alunas ao conhecimento da matemática escolar.

A interação ${ }^{5}$ que vamos analisar iniciou-se com a professora Augusta ${ }^{6}$ retomando o propósito da atividade que tinha sido proposta para o intermódulo ${ }^{7}$ e que nenhum dos alunos tinha cumprido:

\footnotetext{
${ }^{5}$ Os nomes dos estudantes citados nas interações foram escolhidos por eles e, em sua maioria, se referem aos seus próprios nomes indígenas. Todos autorizaram sua divulgação.
} 
DOI: https://doi.org/ 10.20396/zet.v26il.8650482

Professora Augusta: A proposta era pesquisar os modos de medida, o tempo, a temperatura, o volume, a massa, a superfície, a capacidade... Capacidade é isso: a quantidade de farinha, a quantidade de leite, né, utilizados em seu território e que se relacionam com as várias atividades e modos de viver que aparecem no calendário. Aí, depois, discutir qual matéria será elaborada e para quem esse material será elaborado. Isso aqui vocês conseguiram tratar alguma coisa ou não fizeram?

[Silêncio dos alunos]

Professora Augusta: Quando eu falo sistema de medidas, pensando aqui, na aldeia, o que seria interessante pesquisar? Medir o quê? Pensando nas atividades econômicas, nos modos de vida, naquilo que acontece aqui! Onde que as medidas aparecem? Onde é necessário medir?

Patioba: É... No caso da farinha né, peixe...

Professora Augusta: $O$ que mais? [Enquanto conversa, a professora registra no quadro as respostas dos alunos].

Kaiomé: Tem... É... A venda de sementes, né!

Professora Augusta: Venda?

Kaiomé: É, né, que a gente compra as sementes...

Professora Augusta: E aqui tem uma relação com quê? Com o artesanato, né?

Kaiomé: Isso...

Professora Augusta: Com a compra e venda do artesanato, né? Que mais?

Dira: Na hora de fazer a roça...

Professora Augusta: Que mais? Vamos lá gente?

Patioba: $O$ comércio, né?

Professora Augusta: Comércio de quê?

Patioba: Os comércios que tem na aldeia, né!

Kaiomé: E é engraçado, né, que a gente se acostuma chegar nas vendas e pedir: dá um litro de óleo e um litro de farinha...[Risos]...

Taburumã: Professora, eu acho que aí entraria a medida da produção do artesanato, eu acho que estaria aí também!

Professora Augusta: Tá, eu vou colocar!

Haió: Professora, a construção de casas!

Professora Augusta Construção de casas [repete e anota no quadro]... Têm construído muitas casas?

Alunos: Têm sim!

Patioba: Tem a colheita também, né? Acontece também, né, das pessoas colherem...

Professora Augusta: Colher o quê?

Patioba: Colheita de frutas, né! E também as pessoas vendem o coco...

Professora Augusta: Que mais?

Patioba: Melancia né, abacaxi... Que está no momento agora...

${ }^{6}$ Os nomes dos professores, das professoras e das professoras-monitoras citados neste trabalho tiveram sua divulgação autorizada pelos mesmos.

${ }^{7}$ Como o curso é no formato de "Alternância", o currículo está organizando em dois momentos: "Tempo Escola" - em que os/as alunos/as vão à Universidade; e "Tempo Comunidade" - momento em que os/as estudantes desenvolvem atividades em seus territórios e recebem a equipe de professores do curso. 
DOI: https://doi.org/ 10.20396/zet.v26il.8650482

Professora Augusta: Que mais?

Patioba: A mangaba também, as pessoas vendem...

Professora Augusta: Tá! O que mais?

Taburumã: Tem a construção das canoas!

Professora Augusta: Então, a gente podia colocar a pesca, né? Ela envolve o peixe, a construção da canoa, né! Também tem o jeito de pescar, né? E também a venda do peixe... Essa venda, nem sempre é uma venda que me pagam com o dinheiro né, concordam?

Kaiomé: Sim, tem a troca!

Professora Augusta: Hãa! Então eu vou dar destaque aqui, porque eu sei que tem muito esse sistema de troca aqui, não é isso?

Kaiomé: Isso... Até está tendo troca agora...

Professora Augusta: E troca o quê? Peixe, colar...

Patioba: Banana com milho...

Professora Augusta: Oh gente! Alguém podia se debruçar sobre isso aqui? Isso é tão interessante! Isso é muito legal!

Uayã: Vamos uai!

Professora Augusta: $O$ que mais, gente?... Então, aqui nós listamos as várias atividades... Tem mais alguma coisa?... Agora eu queria perguntar uma coisa: essas atividades estão todas dentro do Calendário? Aquele Calendário que vocês elaboraram $^{8}$ ?

Taburumã: Tem mais coisa, mas eu acho que indiretamente está ligado, sim.

Kaiomé: Igual o caso da semente, não está especificado assim lá...

Professora Augusta: Eu fiz um levantamento ontem de todas as atividades do Calendário que envolvem medidas, vejam se vocês concordam... Olhem só a lista que estou fazendo.

[Enquanto isso, ela anotava no quadro as informações].

Professora Augusta: Tem isso aqui também: Sinais da Natureza, isso aqui também é muito forte no Calendário... Eu fiz aqui, vejam se concordam. Ruana, dá uma olhada e nos ajude a verificar se tudo que falamos aqui foi contemplado. [Referindo-se às anotações do quadro] $]^{9}$.

Nessa interação nos chamou a atenção a diferença da participação dos estudantes ao longo da atividade proposta. Ao contrário do que acontece em relação aos primeiros setores da vida social da aldeia listados pela professora, em que eles levantaram uma série de exemplos (do comércio, da colheita, da pesca), sobre os sinais da natureza, nenhum deles acrescentou nada ao que ela havia inserido no quadro que fora montando pela professora na lousa.

Nessa interação, a professora retoma o tema "grandezas e medidas", já trabalhado no módulo anterior (de agosto a setembro daquele ano), através de uma proposta em que os

\footnotetext{
${ }^{8}$ O Calendário a que a professora se refere é uma atividade desenvolvida pelos alunos nas aulas da disciplina Uso do Território.

${ }^{9}$ Os nomes dos estudantes foram escolhidos por eles e, em sua maioria, se referem aos seus próprios nomes indígenas. Todos autorizaram a divulgação.
} 
alunos deveriam narrar as práticas da comunidade, nas quais conceitos associados a tal tema pudessem aparecer.

Percebe-se a preocupação da professora, durante toda a conversa, em aproximar o conhecimento escolar "medir" das práticas cotidianas dos estudantes. Além dessa preocupação, observamos também o seu interesse e até um certo encantamento no diálogo que mantém com seus alunos, sempre numa atitude de valorização da cultura indígena: " $O h$, gente! Alguém podia se debruçar sobre isso aqui? Isso é tão interessante! Isso é muito legal!"

Em contrapartida, os alunos e as alunas não se furtam a apresentar uma série de informações sobre suas práticas tradicionais, de modo a preencher prodigamente o quadro que a professora montava na lousa. Entretanto, se o quadro construído a partir das atividades mencionadas pelos licenciandos indígenas parece completo, é preciso destacar que eles se mostram à vontade para detalhar certas práticas, mas não outras - e não é por não identificarem conhecimentos matemáticos envolvidos nelas. Por uma questão de um sigilo acordado, como um cuidado e até por respeito à aldeia, determinam que muitas coisas não devem ser contadas para "outras" pessoas e devem permanecer no conhecimento apenas do povo Pataxó. É o que parece tê-los feito se calarem em relação aos sinais da natureza, a despeito de a professora os haver mencionado.

Destacamos esse exercício de autocensura que esses sujeitos se impõem porque consideramos que entender essas atitudes ligadas à cultura, como, por exemplo, a noção de patrimônio cultural ${ }^{\mathbf{1 0}}$, é fundamental para a análise de processos de apropriação de práticas discursivas pelos grupos culturais, e, de modo especial, para uma proposta de um curso intercultural, bem como para docentes que lecionam para esses alunos e essas alunas. A desconsideração do tensionamento que esse tipo de zelo com a cultura estabelece na relação dos sujeitos indígenas com aqueles que têm outras referências culturais não só pode gerar situações de conflito menos ou mais explícito nas atividades de formação, mas também pode inviabilizar a potencialização da riqueza que a diversidade pode oferecer a um trabalho intercultural. Diversidade e tensionamento podem se fazer sentir, sob muitos aspectos, na linguagem, nos jogos que a envolvem, nos valores que se atribuem aos conhecimentos e àqueles que os utilizam ou guardam, nas crenças que manifestam ou preservam, nos modos de vida que explicitam ou omitem, que cultivam e transformam, na própria cultura.

Nesse sentido, interessa-nos mobilizar uma ideia de interculturalidade que se aproxima da proposta por Fleuri (2003), citada por Hinojosa \& Lima (2008):

Fleuri ainda amplia o conceito de interculturalidade e o define como uma forma de superar as barreiras culturais que separam do "outro", construindo uma predisposição

\footnotetext{
10 Os bens materiais e imateriais, tangíveis e intangíveis que compreendem o patrimônio cultural são considerados "manifestações ou testemunho significativo da cultura humana" e reputados como imprescindíveis para a conformação da identidade cultural de um povo. [...] O valor cultural, a dimensão simbólica que envolve a produção e a reprodução das culturas, expressas nos modos de uso dos bens, foi incorporado à definição do patrimônio (ZANIRATO \& RIBEIRO, 2006 p. 252).
}

Zetetiké, Campinas, SP, v.26, n.1, jan./abr. 2018, p.133-146

ISSN 2176-1744 
DOI: https://doi.org/ 10.20396/zet.v26i1.8650482

para a leitura positiva, para uma multiplicidade cultural e social capaz de promover a reconstituição do próprio indivíduo. Apesar da polissemia terminológica, considera-se educação inter ou multicultural o conjunto de propostas educacionais e pedagógicas que têm interesse em estimular relações de respeito e integração entre diversos grupos socioculturais, dentro de uma perspectiva dialógica (p.3).

A partir da proposta de uma educação diferenciada, o currículo desse Curso de Formação foi pensado na perspectiva da interculturalidade, incluindo tanto disciplinas que se relacionam ao conhecimento do mundo não indígena, como disciplinas que se relacionam ao contexto da tradição indígena. A combinação dessas disciplinas demanda a produção de materiais didáticos e paradidáticos que contemplem demandas e contribuições específicas da escola indígena. De acordo com Grupioni (2002, p.13), apud Leite (2008, p. 40) esses

novos profissionais indígenas demandam, junto com suas comunidades, uma formação específica, que lhes permita concluir a escolarização básica e obter uma formação em magistério e/ou curso superior (grifo nosso), de modo que possa exercer uma educação qualificada em benefício das crianças indígenas.

As narrativas dos sujeitos e todo o processo de interação que compõe o evento que aqui apresentamos e outros tantos que testemunhamos durante o acompanhamento da turma evidenciam a preocupação dos alunos e das alunas indígenas em trazer sempre as práticas tradicionais e a cultura da aldeia para o centro da discussão, valorizando-as e creditando à sua mobilização na cena escolar a responsabilidade de se construir uma escola indígena diferenciada, que tenha sempre a cultura Pataxó em sua centralidade. Isso fica claro em alguns comentários dos alunos durante a avaliação final das disciplinas específicas de matemática, ocorrida no dia 6 de abril de 2011:

Taburumã: A escola indígena precisa ter um ensino diferenciado... Precisamos ter o nosso material didático, porque o material didático que chega às escolas através do MEC massacra nossa cultura.

(...)

Uayã: Antes de tudo, a gente tem que ouvir a história do nosso povo, contar a história do nosso povo, para depois inserir a história do não indígena; precisamos trabalhar em conjunto, a parte indígena com o não indígena, mas, a cultura indígena tem que estar no centro.

(...)

Wrukurunã: Conhecer a cultura ocidental é importante, desde que ela não ocupe o lugar da nossa cultura.

(...)

Uayã: Fiquei feliz, porque todos os grupos focaram a cultura, isso mostra que estamos no mesmo objetivo; pela cultura, é uma forma dos alunos pegarem mais rápido.

As interações que compõem o primeiro evento aqui narrado nos permitem reforçar a compreensão que temos tido das práticas matemáticas como práticas discursivas, uma vez que tais práticas são "o lugar de manifestações do individual e do social na linguagem" (Bautier, 1995, p.203 apud Schneuwly \& Dolz, 1997, p. 6). Por isso, procuramos destacar as posições assumidas pelos estudantes quando, em seu discurso sobre práticas matemáticas da 
aldeia, motivado pela atividade escolar, põem em relação a cultura tradicional e a cultura escolar. É nas práticas discursivas que tematizam práticas matemáticas tradicionais que os estudantes indígenas elaboram sua relação com as práticas matemáticas escolares, uma vez que "a relação dos atores com as práticas de linguagem também varia e a distância que pode separá-los ou, ao contrário, aproximá-los tem efeitos importantes nos processos de apropriação" (Schneuwly \& Dolz, 1997, p. 6).

A análise que fazemos dessa atitude dos estudantes indígenas de não divulgar certos conhecimentos da aldeia na sala de aula não pretende opor essa negativa à apropriação de uma prática escolar. Pelo contrário, essa atitude parece apontar um certo conhecimento daquela atividade de sala de aula, que os faz avaliar que não é adequado falar ali de certos assuntos. Dessa forma, nosso estudo se aproxima do que foi empreendida por Elsie Rockwell (2010), ao examinar a apropriação da escrita em duas aldeias mexicanas, tendo como sujeitos de seu estudo dois homens ${ }^{11}$ de aldeias distintas, porém, com grande influência em suas comunidades e também em instâncias governamentais. Para a pesquisadora, a questão central "não é saber o que a escrita faz com as pessoas, mas o que as pessoas fazem com a escrita" (Rockwell, 2010 p.84). Ao conversar com esses sujeitos (José Muñoz e Cleofas Galicia), Rockwell deixa claro que o importante no seu estudo não era determinar o quanto os sujeitos dominavam a tecnologia da escrita, ou seja, o saber escrever, e sim o uso que faziam da mesma.

Assim, ela analisa a suposta ambiguidade da relação que eles estabelecem com a emissão de documentos escritos: "a questão era saber o que assinar, quando assinar e o que implicava assinar” (Rockwell, 2010 p.93):

Cleofas diz ter aconselhado os camponeses a não assinar certos documentos apresentados pelos agentes do estado a cargo do desenvolvimento, pois isso os obrigava a pagar por serviços aos quais teriam acesso de qualquer maneira. Por outro lado, ele repreendeu os cobradores que tinham omitido o envio de recibo assinado aos doadores com o intuito de evitar a transparência da contabilidade (p.94).

A apropriação da escrita, nesse exemplo, não se resume apenas no saber escrever o nome, e sim, em conhecer todas as questões envolvidas nessa prática, inclusive suas relações de poder; apropriar-se dessa prática é compreender essas relações, exercendo-a ou se furtando a ela, dependendo do interesse pessoal ou coletivo que está em jogo. É assim que

\footnotetext{
${ }^{11}$ O primeiro sujeito é José Muñoz (Cuauhtenco), nascido em 1925, filho de pais analfabetos e não falantes do espanhol; frequentou a escola por apenas dois anos, porém, destacou-se no exercício da oratória. $\mathrm{O}$ fato de ter interrompido seus estudos não impediu sua aquisição posterior da escrita e "graças a uma sucessão de tarefas públicas, conseguiu dominar a língua espanhola e mais tarde aprendeu a escrever e datilografar diversos tipos de demandas, tornando-se, assim, o representante da comunidade frente ao governo" (Rockwell, 2010 p.89-90). O segundo sujeito, Cleofas Galicia (Xaltipan), cursou três anos do curso primário, do qual muito se orgulhava, também foi responsável por vários comitês e, finalmente em 1980, se tornou agente municipal de Xaltipan (tipo de liderança). Em conversas com a pesquisadora, Cleofas afirmava que conseguia manter o controle sobre as autoridades graças à sua "gestão hábil dos documentos e sua habilidade com a escrita" (Rockwell, 2010 p.9293).
} 
compreendemos a atitude dos alunos e das alunas do Pataxó que se furtaram a prestar maiores informações sobre as práticas sociais da aldeia que envolvem os Sinais da Natureza, contemplando o interesse do grupo que poderia ter sido o de resguardar essas práticas sociais, interesse este, sob certos aspectos, contrário ao da atividade proposta que era justamente o de explicitar as práticas da comunidade de modo a poder, de alguma forma, referir-se a elas ou referenciar-se nelas na abordagem da matemática escolar.

Nessa análise, apoiamo-nos, pois, na concepção de apropriação discutida por Smolka (2000), segundo a qual a

\begin{abstract}
apropriação está relacionada a diferentes modos de participação nas práticas sociais, diferentes possibilidades de produção de sentido. Pode acontecer independentemente do julgamento de uma pessoa autorizada que irá atribuir um certo valor a um certo processo, qualificando-o como apropriado, adequado, pertinente, ou não. Portanto, entre o "próprio" (seu mesmo) e o "pertinente" (adequado ao outro) parece haver uma tensão que faz da apropriação uma categoria essencialmente relacional (p.33).
\end{abstract}

Desse modo, a apropriação se apresenta como um processo que demanda e oportuniza não apenas incorporação, internalização ou mesmo adaptação, mas remete também ao confronto e à crítica, à produção do diverso e do novo. Não se trata, portanto, de um fenômeno de natureza exclusivamente semântica, mas se trata de um processo pragmático de apropriação de procedimentos e discursos.

\title{
"A escola não foi criada para todo mundo": tensões estabelecidas na proposição de um projeto pedagógico para a escola indígena
}

Como vimos na seção anterior, algumas vezes as propostas pedagógicas da escola indígena não conseguem ser solidárias ao ideal de se construir uma escola diferenciada, haja vista os tensionamentos existentes na tentativa de diálogo entre as propostas pedagógicas que querem contemplar a "matemática da tradição" e aquelas que se preocupam em "cobrir o currículo das escolas não indígenas". Essas tensões marcam os discursos dos alunos quando avaliam as práticas pedagógicas que encontram na escola indígena e aquelas, almejadas por esses estudantes, em conformidade com uma proposta de valorização da cultura da aldeia. Diante disso, é que este outro evento contemplará alguns desses tensionamentos que se conformam nas enunciações desses educadores em formação.

Durante as aulas acompanhadas e a partir das narrativas construídas nos eventos anteriores, pudemos perceber a inquietação, vivenciada por esses educadores e essas educadoras, por lidar com duas grandes forças.

Por um lado, encontram-se dispostos a defender a tematização, na escola, da vida da comunidade e da cultura indígena, como uma ação política, em concordância com o discurso da Educação Indígena, já incorporado às orientações dos documentos oficiais direcionados para a Educação Escolar Indígena como um todo. Tais orientações recomendam que o foco seja sempre a realidade dos povos indígenas, sugerindo que as propostas pedagógicas 
incluam a cultura indígena e sua diversidade em todos os seus aspectos "pautados pelos princípios da igualdade social, da diferença, da especificidade, do bilinguismo e da interculturalidade, fundamentos da Educação Escolar Indígena” (BRASIL/CNE/CEB, 2013).

Mas, por outro lado, esses educadores em formação enfrentam o desafio de se implantar essa escola que, embora contemple as necessidades dos povos indígenas, deve também responder a uma série de exigências da, ou de referências na, estrutura da escola não indígena, regida pelos parâmetros do Estado ou do Município, e do sistema de ensino, que determinam seus modos de organização do trabalho pedagógico e de sua avaliação. Também a tradição escolar e as expectativas da sociedade (tanto indígena como não indígena) de certa forma exercem pressão na escolha do que se vai contemplar e mesmo de como os temas serão contemplados. Esse tensionamento fica claro quando os próprios estudantes do curso demonstram não saber qual a proposta ideal de uma escola indígena, ora posicionando-se em defesa de uma escola totalmente diferenciada, ora apresentando um discurso que reforça os valores da escola não indígena, como pode ser percebido na interação que analisamos a seguir.

O evento aconteceu no dia 17 de agosto de 2011. Nesse dia, a aula se iniciou com a

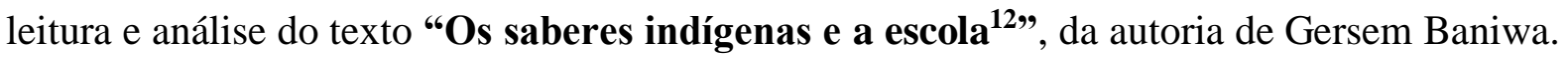
O eixo da discussão proposta pela professora Augusta era "como as práticas atuais da escola indígena se relacionam ou não com os conhecimentos tradicionais (indígenas) e os conhecimentos escolares não indígenas, no que se refere a números e à geometria". Durante os trabalhos, os estudantes destacaram a importância do diálogo intercultural, ou seja, " $a$ obrigação que a escola tem de dialogar com culturas diferentes" (fala de um estudante indígena).

Cabe observar o posicionamento crítico que esses estudantes estabelecem com o texto que se mostra, por exemplo, na reação do aluno Patioba à afirmação do autor de que " $a$ escola indígena não forma bons cidadãos indígenas":

Patioba: Nós devemos ser críticos sobre o que as outras pessoas falam ou escrevem sobre a educação indígena...

Toda a discussão, entretanto, é marcada pela diversidade de posicionamentos e pelos questionamentos que esses educadores indígenas a todo momento propõem ao grupo: "Será que devemos ficar ensinando apenas coisas da cultura?"; "A escola foi imposta para os indios, ela nos forçava a aprender e viver outra cultura que não era a nossa"; "A escola indigena precisa formar o aluno para o mercado de trabalho, para atuar lá fora!”. A crítica que esses enunciados trazem às posições extremadas, seja pela opção por uma abordagem exclusiva de temas da cultura indígena, seja pela submissão total à vida de outra cultura ou às imposições pragmáticas do mercado de trabalho, sugerem que esses estudantes indígenas intuem que a conformação da proposta da Educação Escolar Indígena terá sempre que

${ }^{12}$ Texto apresentado no Encontro Nacional de Didática e Prática de Ensino/ENDIP em Belo Horizonte - 20 a 23 de abril de 2010 . 
considerar esse tensionamento e o desafio de inaugurar um novo paradigma para a instituição escolar, uma vez que, encerrando os comentários do texto discutido na aula, afirmou incisivamente o aluno Taburumã:

Taburumã: A escola, desde o princípio, foi criada para uma sociedade, para a elite europeia, ela não foi criada para todo mundo.

Como reflexo dessa exclusividade do projeto escolar para alguns grupos culturais (" $a$ elite europeia", segundo a análise de Taburumã) e da consequente exclusão de outros grupos, deparamo-nos com a escassez de material didático voltado para os povos indígenas. $\mathrm{O}$ ressentimento em relação a essa escassez é flagrado constantemente nos discursos dos educadores em formação do curso. Mas esses discursos demarcam também o inconformismo com o silenciamento da cultura indígena na escola, além de grande disposição na busca de alternativas e na produção de soluções, como fica claro nas falas que se seguem:

Wrukurunã: A escola indígena mudou um pouco, mas não muito, porque continuamos presos a certas convenções próprias da escola, como notas, horários... Isso tudo precisa mudar;

(...)

Taburumã: Uma das formas que eu acho que a escola indígena poderá ser diferenciada é a criação do nosso próprio material didático.

As limitações de uma proposta de ensino diferenciada, que contemple as preocupações da Educação Escolar Indígena, não se estabelecem, porém, apenas pela falta de materiais e recursos didáticos próprios e/ou adequados ou mesmo pelas tensões exercidas pela força da própria cultura escolar em contraposição a um ideal de escola que atenda às demandas e perspectivas específicas das comunidades indígenas. Entendemos que a Educação Escolar Indígena sofre os, se alimenta dos e contribui para os efeitos da conformação de uma nova vida na aldeia, desencadeada pelas lutas e pelas conquistas do movimento indígena, entre as quais as que se referem à demarcação de seus territórios:

"Antes, nós não tinha o direito porque não tínhamos conhecimento. Hoje, nós temos o conhecimento; os jovens, por isso, temos nosso direito garantido".

(Fala de uma liderança Pataxó durante a assembleia final do módulo do primeiro semestre, dia 15 de abril de 2011).

\section{Algumas considerações}

$\mathrm{Na}$ composição deste artigo, evidenciamos as tensões existentes nos processos de apropriação de práticas discursivas no contexto de formação de educadores indígenas, como pode ser visto nos eventos "Matemática no Calendário do Conhecimento Pataxó" e "A escola não foi criada para todo mundo". A análise desses eventos nos mostrou que é preciso considerar o contexto mais amplo das relações com a cultura indígena e com a cultura escolar, uma vez que agrega aos processos de apropriação, complexidades decorrentes das contradições dos discursos que informam lutas e conquistas. 
DOI: https://doi.org/ 10.20396/zet.v26il.8650482

Tais contradições, entretanto, não são aqui analisadas como entraves à apropriação. Ao contrário, queremos destacar o seu potencial produtivo na constituição desses sujeitos, educadoras e educadores indígenas, não só como executores de práticas pedagógicas préestabelecidas, mas como críticos e propositores de novas práticas.

Portanto, nossa análise indica a possibilidade de pensarmos em uma Educação Escolar Indígena, em que seja contemplado muito mais do que habilidades matemáticas. Ela aponta para a compreensão dos modos como os educadores e as educadoras indígenas em formação significam e constroem formas próprias de participar das práticas discursivas de matemática da escola ou da aldeia. Tais processos de apropriação são complexos e nos colocam outras demandas e possibilidades a que os educadores e as educadoras indígenas e seus formadores e suas formadoras devem estar atentos.

Esses movimentos, tensos e complexos, são aqui considerados como constitutivos dos processos de apropriação dessas práticas e dos discursos que as conformam, assumindo uma compreensão desses processos numa perspectiva que encontramos em Smolka (2000) e em Bakhtin (1997; 1997a) e que supõe que as relações nas quais os sujeitos estão envolvidos constituem fatores imprescindíveis na explicação dos seus modos de viver, modos de ser, modos de conhecer e modos de se relacionar, ou seja, definem o campo de possibilidades no qual os sujeitos desempenham sua autonomia nos processos de compreensão do mundo.

\section{Referências}

Bakhtin, M. M. (1997). Estética da criação verbal. São Paulo: Martins Fontes.

Bakhtin, M. (1997a). Marxismo e filosofia da linguagem. São Paulo: Hucitec.

Braint, Beth. (2006). Bakhtin: outros conceitos-chave. São Paulo: Contexto.

Baniwa, G. S. L. (2010). Os saberes indígenas e a escola. Encontro Nacional de Didática e Prática de Ensino/ENDIP. Belo Horizonte. Retirado em 20 de março, 2010, de: http://www.cinep.org.br/uploads/580272e6a30f763675251a3e394524baef26de85.pdf.

Bautier, E. (1995). Pratiques langagières, pratiques sociales: de La sociolinquistique à la sociologie Du langage. Paris: L'Harmattan.

Brasil. (2013). Lei de Diretrizes e Bases para a Educação Indígena. Ministério da Educação. Secretaria de Educação Básica. Secretaria de Educação Continuada, Alfabetização, Diversidade e Inclusão. Secretaria de Educação Profissional e Tecnológica. Conselho Nacional da Educação. Câmara Nacional de Educação Básica. Brasília: MEC, SEB, DICEI. (374p).

Brito, R. P. S., \& Fonseca, M. C. F. R. (2017). Apropriação de práticas discursivas da matemática escolar: considerações a partir de uma experiência de formação intercultural de educadores indígenas. Bolema, 31(58), 542-563.

Chartier, R. (2003). Leituras e leitores na França do antigo regime. Tradução Álvaro Lorencini. São Paulo: UNESP.

Ferreira, M. K. L. (2002). Ideias matemáticas de povos culturalmente distintos. São Paulo: Global.

Zetetiké, Campinas, SP, v.26, n.1, jan./abr. 2018, p.133-146

ISSN 2176-1744 
DOI: https://doi.org/ 10.20396/zet.v26il.8650482

Fleuri, R. A. (2003). Intercultura e educação. Revista Brasileira de Educação, 23, 16-35.

Fonseca, M. C. F. R. (2009). Conceito(s) de numeramento e relações com o letramento. In C. E. Lopes \& A. D. Nacarato. Educação Matemática, leitura e escrita: armadilhas, utopias e realidade. Campinas, SP: Mercado das Letras.

Grupioni, L. D. B. (2002). Educação Escolar Indígena: formação de professores. Retirado em 17 de outubro, 2010, de: www.redebrasil.com.bre/salto/boletim2002/eei/eei0htm.

Hinojosa, F. R \& Lima, R. (2008). A tradução como estratégia de interculturalidade no ensino de língua estrangeira. Retirado em 17 de outubro, 2010, de: http://www.bocc.ubi.pt/pag/lima-hinojosa-traducao-estrategia-interculturalidade.pdf.

Leite, L. H. A. (2008). Os professores indígenas chegam à universidade: desafios para a construção de uma educação intercultural. In: Pereira, J. H. D \& Leão, G. (orgs). Quando a diversidade interroga a formação docente. Belo Horizonte: Autêntica.

Rockwell, E. (2010). L'appropriation de lécriture dans deux villages nahua du centre Du Mexique. Langage et Société, 133, 83-99.

Schneuwly, B., \& Dolz, J. (1997). Os gêneros escolares: das práticas de linguagem aos objetos de ensino. Publicado originalmente em Repères, 15, 1997, sob o título "Les genres scolaires: des pratiques langagières aux objets d'enseignement". Retirado em 20 de abril, 2011, de: http://educa.fcc.org.br/pdf/rbedu/n11/n11a02.pdf.

Smolka, A. L. B. (2000). O (im)próprio e o (im)pertinente na apropriação das práticas sociais. Cadernos Cedes, 50, 26-40.

Zanirato, S. H \& Ribeiro, W. C. Patrimônio cultural: a percepção da natureza como um bem não renovável. Retirado em 20 de maio, 2012, de: $\mathrm{http}: / / \mathrm{w} 3 . u f s m$. br/ppgppc/index.php?option=com_content $\&$ view $=$ article $\& \mathrm{id}=105: 0-$ que-atrim-cultural-patrim-histo-patrim-ambiental-ounatural\&catid=7: examples \&Itemid $=25$.

Recebido em: 01/10/2017

Aprovado para publicação em: 11/03/2018 